\title{
An LFG Analysis of Gapping Constructions in Taif Arabic
}

\author{
Muhammad Swaileh A. Alzaidi*
}

Department of English Language and Literature, King Saud University, PO box 2456, Riyadh 11451, Kingdom of Saudi Arabia

Corresponding Author: Muhammad Swaileh A. Alzaidi, E-mail: malzaidi1@ksu.edu.sa

\section{ARTICLE INFO}

\section{Article history}

Received: April 11, 2018

Accepted: August 26, 2018

Published: October 31, 2018

Volume: 9 Issue: 5

Advance access: August 2018

Conflicts of interest: None

Funding: None

\begin{abstract}
We identify and propose an analysis in LFG of Gapping construction in Taif"Hijazi” Arabic (TA). Gapping occurs in a coordination structure where the initial conjunct is syntactically complete and the non-initial conjunct is incomplete. To my knowledge, there is no previous description or analysis of gapping in TA. There have been two competing analyses in the literature on gapping, which view gapping as a result of a trace of movement and non-constituent coordination. In this paper, we show that none of these approaches succeeds to account for Gapping in TA, and hence, they fail to capture the facts of gapping in this Arabic dialect. Instead, we adopts a functionspreading approach within Lexical-Functional Grammar (LFG), and show how it is able to account for the facts of gapping in TA, using mechanisms proposed independently for other construction types.
\end{abstract}

Key words:

Gapping,

Coordination,

Ellipsis,

Remnant,

Lexical Functional Grammar

\section{INTRODUCTION}

This paper is concerned with gapping constructions in Taif "Hijazi" Arabic (TA) (a Hijazi Arabic variety spoken in Taif) in which the initial conjunct is syntactically complete and the non-initial conjunct is missing the verb(s). This is exemplified in English in the following example (missing materials appear in strike-thu).

(1) $\left\{\left[{ }_{\alpha}\right.\right.$ John drinks coffee $]$ and $\left[{ }_{\gamma}\right.$ Peter tea $\left.]\right\}$.

The verb of the non-initial conjunct (e.g., $\gamma$ ) is deleted under identity with that of the initial-conjunct (e.g., $\alpha$ ). Therefore, the non-initial conjunct shares the missed elements that are overtly spelt-out in the initial conjunct. Following usual terminology, we call the missing material the Gap, the initial conjunct (e.g., $\alpha$ ) the antecedent clause, the non-initial conjunct (e.g., $\gamma$ ) the gapped clause, and the remaining elements in the gapped clause remnants.

Gapping has distinctive features that make it different from other syntactic constructions. For example, Gapping differs from Verb Phrase Ellipsis (VPE) and Pseudo-gapping. In VPE constructions, the main predicate with its argument are missing as in (2) below (Sag, 1976). Therefore, VPE differs from gapping as illustrated in (1) above.

(2) John drinks coffee, and Peter does drink coffee too.

Moreover, Gapping differs from Pseudogapping constructions, as illustrated in (3) below (Levin, 1986). In pseudogapping construction as in (3), the auxiliary is not removed whereas the main verb is removed.

(3) John has drunk coffee and Peter has tea.

To our knowledge, there is no previous description or analysis of gapping in TA. However, there are many approaches proposed to account for gapping in other languages including English and Russian. One of the approaches within a derivation approach (i.e., in Minimalism framework) is proposed by Johnson (2004) who claims that Gapping in English (e.g. as in Some people speak to Sal and others to Henry) is a result of $\mathrm{A}$ (cross)-T(he)-B(oard) movement of the verbs from each member of a coordinate structure. In non-derivational approach as in LFG framework, Maxwell and Manning (1996) propose the use of F(inite)-S(tate)-A(utomata) in a surface based approach to non-constituent coordination, suggesting that such an account might afford an analysis of gapping as a case of non-constituent coordination. ${ }^{1}$ However, such approaches cannot be extended to cover TA data presented in this structure. In other words, they cannot account for the facts of gapping in TA presented in the current paper.

Therefore, this paper has three aims. First, it aims to identify the gapping constructions in TA and its properties. Second, it aims to show how previous approaches including Johnson (2004) and Maxwell and Manning (1996) fail to account for TA gapping. Finally, it will provide analysis 
of TA gapping within LFG; framework adopting a function spreading approach and show how it is able to account for the facts of gapping in TA, using mechanisms proposed independently for other construction types.

This paper is structured as follows. Section 2 outlines the basic characteristics of TA including word order, simple and compound morphosyntactic tenses. Section 3 presents the issue and the properties of gapping in TA. Section 4 presents first a brief overview of two previous approaches (i.e., Johnson's (2004) transformational approach, and Maxwell and Manning's (1996) LFG approach) proposed to account for gapping in languages including English. Then, it shows how they fail to account for the gapping in TA. Section 5 introduces the LFG approach to constituent coordination through discussion of sentential coordination patterns in TA. Then, it will present our function spreading approach to gapping in TA and show how it is able to account for the facts presented in Section 3. Section 6 concludes the paper.

\section{TAIF ARABIC (TA)}

Taif Arabic is a variety of Hijazi Arabic spoken in Taif city, Kingdom of Saudi Arabia as shown in Figure 1. The syntax of this dialect receives little attention in the literature (Alotaibi, 2014). TA, likes Arabic in general, is a head-initial language, albeit has a free pattern of word order.
In TA, the following word patterns are possible (VO), (VSO), (SVO), (VOS), (OVS), (OSV), as in (4) below (the last two with an optional pronominal affix doubling the object). Irrespective of its position, the verb displays full agreement with the subject.

$$
\begin{aligned}
& \text { (4) a. 'akal ar-ruz. (VO) } \\
& \text { eat.pfv. } 3 \mathrm{sm} \text { the-rice } \\
& \text { 'He ate the rice.' } \\
& \text { b. 'akal } \text { 'ali ar-ruz. (VSO) } \\
& \text { eat.pfv.3sm Ali the-rice } \\
& \text { 'Ali ate the rice.' } \\
& \text { c. 'ali 'akal ar-ruz. (SVO) } \\
& \text { Ali eat.pfv. } 3 \mathrm{sm} \text { the-rice } \\
& \text { 'Ali ate the rice.' } \\
& \text { d. 'akal ar-ruz ৎali. (VOS) } \\
& \text { eat.pfv. } 3 \mathrm{sm} \text { the-rice Ali } \\
& \text { 'The rice, Ali ate.' } \\
& \begin{array}{lll}
\text { e. ar-ruz 'akal-(uh) } & \text { 'ali. } & \text { (OVS) }
\end{array} \\
& \text { the-rice eat.pfv.3sm-it.sm Ali } \\
& \text { 'The rice, Ali ate (it).' }
\end{aligned}
$$

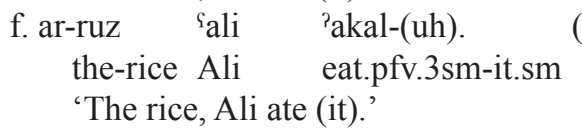

In the examples (5) and (6) below, the simple and compound morphosyntactic tenses in TA are exemplified. Sentence $(5 \mathrm{~b})$ can be either simple present or present simple

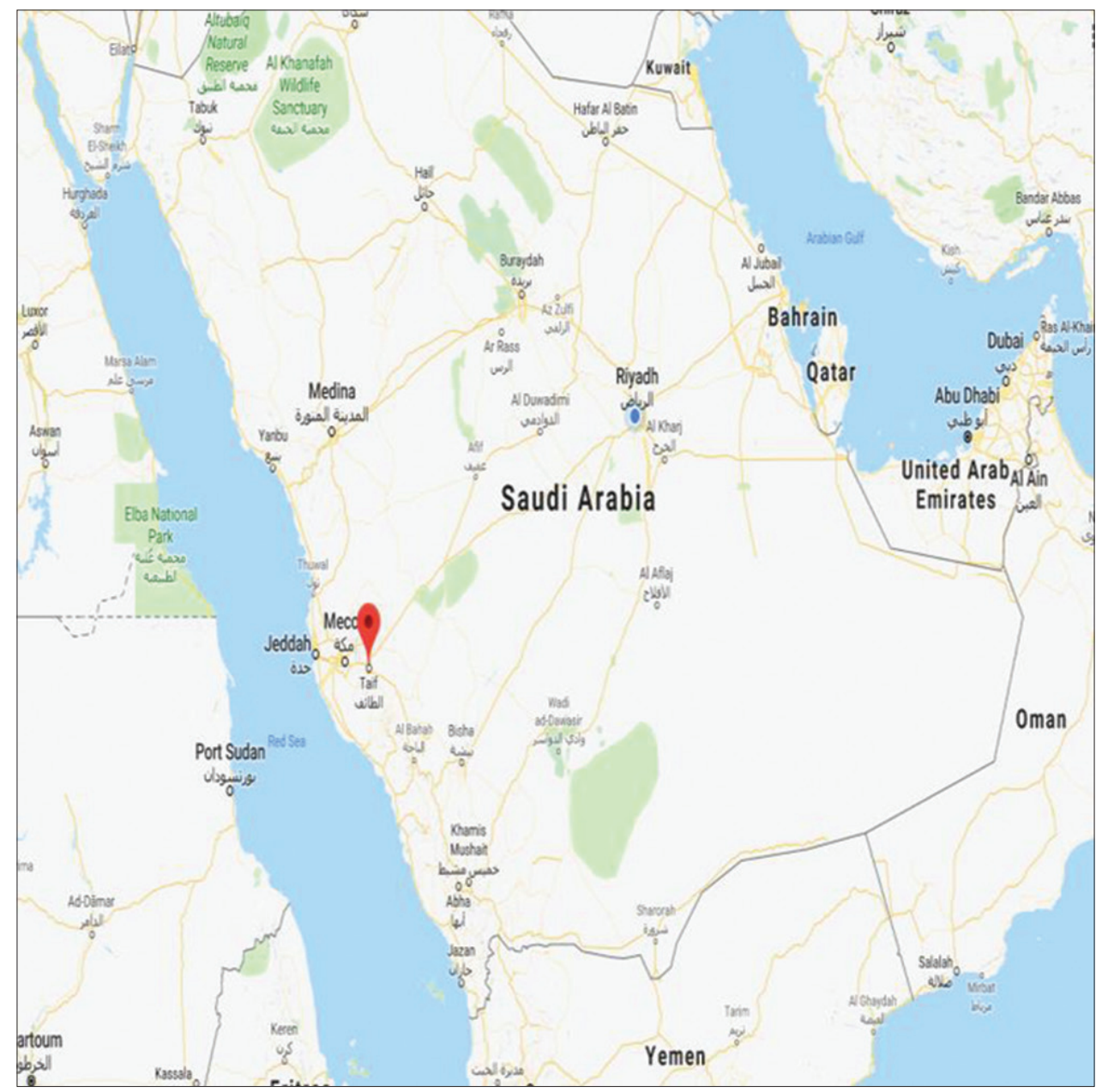

Figure 1. Map: Kingdom of Saudi Arabia (Taif city) 
continuous. The interpretation of $6 a$ ) can be either past progressive or habitual progressive, $y u k u$ : $n$ with an imperfective form of the lexical verb yields a present progressive interpretation, as in (6b), and $y u k u$ : $n$ with a perfective form of the lexical verb yields a present perfect interpretation, as in (6d).

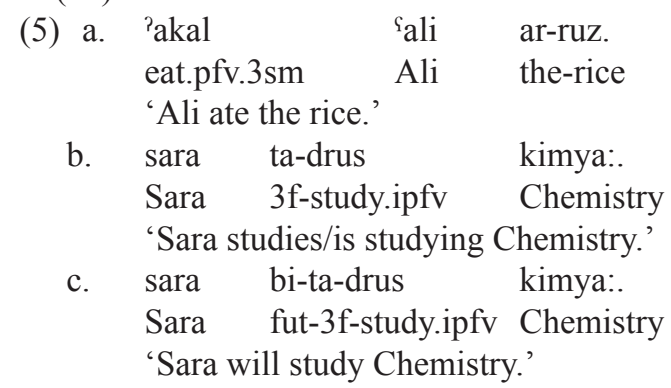

(6) a. 'aћmad ka: n yuktub qasiidah.

Ahmad be.pfv.3sm write.ipfv. $3 \mathrm{sm}$ poem

'Ahmad was writing/used to write a poem.'

(Alotaibi 2014:36)

b. 'ahmad yuku: n yuktub qasidah.

Ahmad be.pfv. $3 \mathrm{sm} \quad$ write.ipfv. $3 \mathrm{sm}$ poem

'Ahmad is writing a poem.'

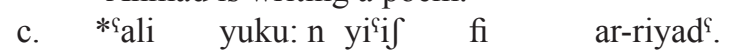
Ali be.pfv.3sm in the-Riyadh

'Ali is living in Riyadh.' (Alotaibi 2014:39)

d. 'ahmad yuku: n katab qasidah.

Ahmad be.pfv. $3 \mathrm{sm} \quad$ write.pfv. $3 \mathrm{sm}$ poem

'Ahmad has written a poem.'

In this section, we presented the permissible word orders, and the simple and compound morphosyntactic tenses in TA. We noticed that verbs in TA agree with its subject in gender, number and person. In the following section, we will present the issue and properties of gapping in TA.

\section{THE ISSUE AND PROPERTIES OF GAPPING IN \\ TA}

The properties of gapping in many languages including English (Johnson, 2004), Russian (McShane, 2005), Chinese (Paul, 1999), Korean (Kang, 1996), German (Repp, 2009) and Jordanian Arabic (Albulkhari, 2016) have been discussed in the literature. Based on these studies, the properties of gapping in TA will be identified in this section.

First, Jackendoff (1971), Handkamer (1979), Moltmann (1992), Lechner (2004), McShane (2005), Wynægrd (2007), Johnson (2009), and among others notice that gapping operates in non-initial conjuncts unlike verb phrase ellipsis (VPE), as in (7) below.

(7) *Sue the lamb, but John will have the salmon.

Second, gapping is restricted to symmetrical coordination as in (8a) and may occur in (symmetrical) comparative structure as in ( $8 \mathrm{~b})$. In subordinating conjunctions and asymmetric coordination, gapping is not possible as in (8c).

(8) a. John likes bananas, and Sally pears. (Wyngærd, 2007: 2)

b. The old man looked at his dog like a lover at his beloved. (McShane, 2005: 136)

c. *Mary cooked dinner on Tuesday because Peter on Wednesday. (ibid.)
Third, gapping does not operate out of, or into, embedded conjuncts. An example from English is in (9) below.

(9) *Amanda went to Santa Cruz, and Bill thinks that Claire to Monterrey. (Vicente, 2010: 209)

Fourth, gapping is subject to a parallelism constraint, excluding, for example, active/passive mismatches (unlike VPE). The examples in (10) below illustrate.

(10) a. *That should be explained to individual students by the TA, but the professor to the class in general.

(Gapping Construction)

b. That can all be explained, and the professor. (VPE Construction)

Fifth, gapping is recursive in that the initial conjunct can be followed by any number of conjuncts which lack materials present in the initial conjunct as in (11) below (McShane, 2005). (11) Jane's birthday is in May, John's in June, and Rex's in July. (McShane, 2005: 138)

The final property of gapping is that across-the-board extractive (ATB) from coordinate structure is possible, as exemplified in (12) below.

(12) What did Mary tell Jon and Peter Susan?

Similar effects can be shown for Taif Arabic. In the following, we identify eleven properties of Gapping in this Arabic vernacular. First, TA gapping requires an overt syntactic antecedent. That is, there is no backward anaphora as in VPE. An example is in (13) below.

(13) a. $\{[$ '́ali 'akal ar-ruz] w [xa: lid 'akal al-laћam]\}.

Ali eat.pfv. $3 \mathrm{sm}$ the-rice and Khaled eat.pfv. $3 \mathrm{sm}$ the-meat

'Ali ate the rice, Khaled the meat.'

b. * $\{[$ '́ali $\quad$ ar-ruz $]$ w $\quad$ [xa: lid 'akal ? a 1 laћam]\}

Ali the-rice and Khaled eat.pfv. $3 \mathrm{sm}$ th e meat

'Ali ate the rice, and Khaled ate the rice.'

Second, Gapping in TA does not occur with a subordinating conjunction, as illustrated in (14) below.

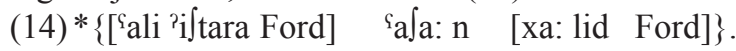

Ali buy.pfv.3sm Ford because Khaled Ford

Intended: 'Ali bought Ford because Khaled bought Ford.'

The third property of TA gapping is that it cannot occur in a (symmetrical) comparative structure as shown in (15) below. (15) * \{['ali ?akal ar-ruz $]$ ? ak $\theta$ ar min-ma [xa: lid ?al-laham]\}.

Ali eat.pfv. $3 \mathrm{sm}$ the-rice more from-that Khaled the-meat

'Ali ate more rice than Khaled the meat.'

In TA, gapping into a conjunct embedded position is impossible. This is illustrated in (16) below.

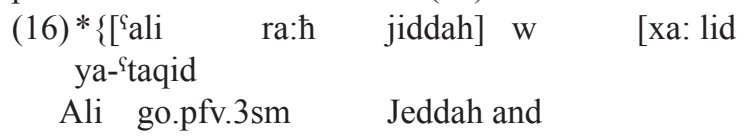

Khaled $3 \mathrm{~m}$-think.ipfv.3plm

'in faisal ra:h ar-riya: $\left.\left.d^{\varsigma}.\right]\right\}$.

that Faisal go.pfv.3sm the-Riyadh

Intended: 'Ali went to Jeddah, and Khaled thinks that Faisal went to Riyadh.' 
In addition, TA gapping from a conjunct embedded position is impossible as exemplified in (17) below (see also Albukhari (2016: 56-57) for Jordanian Arabic).

(17) \{[faisal qa: 1 'lali 'akal ar-ruz, ] w [xa: lid 'allaham]\}.

Faisal say pfv.3sm Ali eat.pfv.3sm the-rice and Khaled the-meat

Intended: 'Faisal said that Ali ate the rice, and Khaled ate the meat.'

In TA gapping, the initial conjunct can be followed by a number of conjuncts in which they lack material(s) overtly spelt out in the initial conjunct. This is exemplified in the following example.

(18) $\left\{\left[\right.\right.$ ['ali ra:h jiddah] w [xa: lid ar-riya: $\left.d^{\mathrm{S}}\right] \mathrm{w}$
[faisal
Ali go.pfv.3sm $\quad$ Jeddah] and Khaled
the-Riyadh and $\quad$ Faisal
'al-ba: aha] w [bader Makkah].
the-BahA and Bader Makkah

'Ali went to Jeddah, and Khaled Riyadh, Faisal Baha, and Bader Makkah.'

Like English, ATB extraction from the coordinate structure is possible in TA gapping. This is shown clearly in (19) below.

(19) mata ${ }^{\text {cali }}$ ra:h jiddah w xa: lid ar-riya: $d^{\varsigma}$. when Ali go.pfv.3sm Jeddah and Khaled the-Riyadh

'When did Ali go to Makkah and when did Khaled go to Riyadh?'

Furthermore, gapping is possible in all possible orders in the antecedent (conjunct) clause. This is demonstrated in the following examples.
(20)a. $\{[$ 'akal ar-ruz] w $\quad$ [xa: lid 'al-laham]\}. $\mathrm{V} \quad \mathrm{O}$ and $\mathrm{S}$ O eat.pfv. $3 \mathrm{sm}$ the-rice and Khaled the-meat 'He ate the rice, and Khaled the meat.'

b. $\{$ ['akal $\quad$ ali ar-ruz $] \mathrm{w} \quad[\mathrm{x} \mathrm{a}: 1 \mathrm{id}$ ?al-laham]\}.

$\mathrm{V} \quad \mathrm{S} \quad \mathrm{O}$ and $\mathrm{S}$ O
eat.pfv.3sm Ali the-rice and $\mathrm{K} \mathrm{h}$ a $\mathrm{l} \mathrm{e} \mathrm{d}$ the-meat

'Ali ate the rice, Khaled the meat.'

c. $\{[$ '`ali 'akal ar-ruz $]$ w laћam]\}.

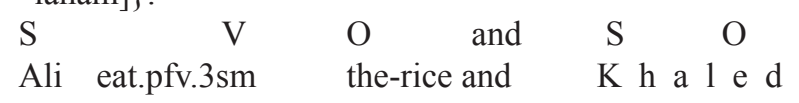
the-meat

'Ali ate the rice, and Khaled the meat.'

d. \{['akal ar-ruz $\varsigma^{2}$ ali] W [xa: lid ? a 1 laham]\}.

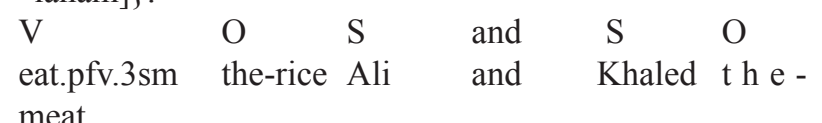

'Ali ate the rice, and Khaled the meat.'

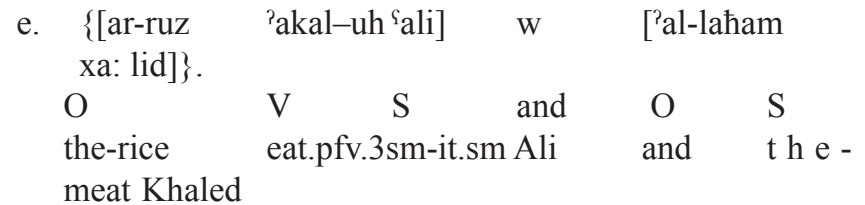

'Ali ate the rice, and Khaled the meat.'

f. $\{[$ ar-ruz $\quad$ ali 'akal] W ['al-laћam xa: lid] $\}$.

O S $\mathrm{V}$ and $\mathrm{O}$ S

the-rice Ali eat.pfv.3sm and $\mathrm{th} \mathrm{e}-\mathrm{m}$ e a $\mathrm{t}$

Khaled

'Ali ate the rice, and Khaled the meat.'

Another property is that gapping is possible with all the available conjunctions $w$ 'and', 'aw 'or', bas/la: kin 'but', 'imma...walla 'either.or', and finally la ....wala 'neither... nor'. These are exemplified below.

(21)a. xa: lid ra:h jiddah w sa: rah ar-riya: $d^{\complement}$.

Khaled go.pfv.3sm and $\mathrm{S}$ a $\mathrm{r}$ a $\mathrm{h}$ the-Riyadh

'Khaled went to Jeddad, and Sara to Riyadh.'

b. `ali ya-l'ab ku: rah ?aw xa: lid tennis.

Ali 3m-play-ipfv football or Khaled tennis 'Ali plays/is playing football, or Khaled tennis.'

c. xa: lid ra:h jiddah bas/la: kin

sa: rah ar-riya: $d^{\text {` }}$.

Khaled go.pfv.3sm Jeddah but Sarah the-Riyadh

'Khaled went to Jeddad, but Sara to Riyadh.'

d. 'immaxa: lid ra:h jiddah] bas/la: kin sa: rah ar-riya: $d^{\complement}$.

either Khaled go.pfv.3sm Jeddah but

Sarah the-Riyadh

'Either Khaled went to Jeddad or Sara to Riyadh.'

Moreover, in the gapping constructions the members of coordinate structure share temporal and aspectual properties. This is illustrated in (22) below.

(22) a. 'al-wla: d ha-yu-drus-un kimya w'al-bana: $t$ fizya.

the-boys fut-3m-study-ipfv-pl-ind Chemistry and the-boys Physics

'The boys will study Chemistry, and the girls (will study) Physics.'

b. אali ka: $n \quad$ yuktub risa: lah $w \quad$ xa: lid $q$ a sidah.

Ali be.pfv.3sgm write.ipfv.3sm letter and Khaled poem 'Ali was writing/used to write a letter, and Khaled a poem.' In (22a), the verb $\hbar a-y u$-drus-un 'will-study' is inflected with future tense marker ( $h a-)$, present tense ( $y u$-) (i.e., imperfective), and indicative mood (-un). This information spelt out in the first conjunct is as same as the information missed in the second conjunct. That is, tense and mood cannot be different in both conjuncts (i.e., two events). In (22b), the auxiliary $k a$ : $n$ is used with another verb yuktub (i.e., must be in imperfective form) to express a various types of tense and mode (i.e., ambiguous between past progressive and habitual progressive). The auxiliary ka: $n$ with the verb yuktub spelt out in the first conjunct is gapped in the second conjunct. If the gapped clause in (22b) is completed, the structure should be as in (23) below.

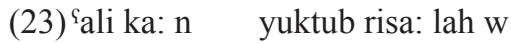 xa: lid ka: $n$

Ali be.pfv.3sgm write.ipfv. $3 \mathrm{sm}$ letter and

Khaled be.pfv.3sgm

yuktub qas ${ }^{\complement}$ idah.

write.ipfv. $3 \mathrm{sm}$ poem 
'Ali was writing/used to write a letter, and Khaled was writing/used to write a poem.'

TA example corresponding to English pseudo-gapping (as in sentence 3 above) is ungrammatical. This is illustrated in the example below.
(24) $*$ a ali
ka: $n$
y u k t u b

risa: lah $w \quad$ xa: lid ka: $\mathrm{n}$

Ali be.pfv.3sgm write.ipfv. $3 \mathrm{sm}$ letter and Khaled be.pfv. $3 \mathrm{sgm}$

qasiidah.

write.ipfv. $3 \mathrm{sm}$ poem

Intended: 'Ali was writing/used to write a letter, and

Khaled was writing/used to write a poem.'

In (24), the verb yuktub 'write' preceding the auxiliary $k a: n$ is gapped in the non-initial conjunct, and hence, it results in being ungrammatical.

As for agreement properties, members of the coordinate structure do not necessarily share them. The examples below illustrate. In (25a), the verbally incorporated subject in the first conjunct is not shared into the gapped clause. If the verbally incorporated subject in the gapped clause is spelt out, it should be as in (25b). Bing so, the morphological agreement displayed in the initial conjunct is not as same as the one in the non-initial conjunct.

(25)a. xa: lid ra: $\hbar$ jiddah w sa: rah ar-riya: $d^{\mathrm{S}}$.

Khaled go.pfv.3sm Jeddah and Sarah the-Riyadh

'Khaled went to Jeddad, and Sara to Riyadh.'

b. xa: lidra:h jiddah $\quad \mathrm{w} \quad$ sa: rah ra:h-at ar-riya: $d^{\varsigma}$.

Khaled go.pfv.3sm and Sarah go.pfv-3sf the-Riyadh

'Khaled went to Jeddad, and Sara went to Riyadh.'

The final property of TA gapping is that the remnants in the gapped clause do not necessarily follow the order of their correspondents in the antecedent clause in the syntax as wshown in (26) below.

(26) 'ali ?akal ar-ruz w ?al-laћam xa: lid.

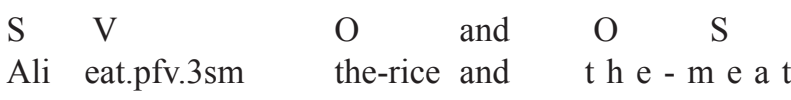

Khaled

'Ali ate the rice, and Khaled the meat.'

In (26), the complement of the missed verb 'al-laћam 'the-meat' is syntactically realized before the subject Khaled. This indicates that the word order exhibited in the non-initial conjunct(s) in TA gapping constructions is not necessarily required to be as same as the word order exhibited in the initial conjunct.

In this section, we demonstrate that some properties of gapping in TA are similar to the properties of gapping in English, and hence gapping as a syntactic construction exists in TA. In addition, we discussed the properties and the issue of the TA gapping. In the following section, we will discuss previous approaches proposed to account for gapping in languages including English and Jordanian Arabic. In this section, we will show that none of these approaches is about to account for the facts of TA gapping presented in this section.

\section{EXISTING APPROACHES TO GAPPING}

To account for gapping constructions in languages including English, approaches are proposed in the literature. One of the approaches within derivational framework is that gapping is interpreted as a trace of ATB movement (Johnson, 2004). This approach is adopted by Albulkhari (2016) to account for gapping constructions in Jordanian Arabic.

Following Johnson (2004), Albulkhari (2016) interprets gapping in Jordanian Arabic as a result of a low-coordination vP. He claims that the verb is moving Across the Board (ATB) from both conjuncts into $T$ thereabouts, as in (34b), roughly. (27) a. hassan Jtara sajjara, w 'umar be: $t$.

Hassan buy.3sm.per car and Omar house

'Hasan bought a car, and Omar a house.'

b. [TP hassan ${ }_{1}\left[\operatorname{tara}_{3}\left[\operatorname{predP}\left[\mathrm{vp} \mathrm{t}_{3} \mathrm{t}_{2}\right] \ldots\left[\mathrm{vP} \mathrm{t}_{1}\left[\mathrm{vP} \mathrm{t}_{3}\right.\right.\right.\right.$ sajjara $\left.\left.{ }_{2}\right]\right] \mathrm{w}\left[\mathrm{vP}^{\varsigma}\right.$ umar $\left.\left[\mathrm{vPt}_{3} \mathrm{t}_{2}\right]\right]$ be: $\left.\left.\left.\mathrm{t}_{2}\right]\right]\right]$

It is not clear how this movement approach could account for the range of attested TA cases presented in Section 3, including agreement and word order mismatches.

Within non-derivational approach (i.e., LFG framework), Maxwell and Manning (1996) propose the use of FSA-based rule factorization as an approach to non-constituent coordination, and suggest that such an account might afford and analysis of gapping as a case of non-constituent coordination. They apply their 'rule-splitting' approach to non-constituent coordination such as (28).

(28) a. John gambled in Sydney on Monday and in Monaco on Thursday.

b. c-structure

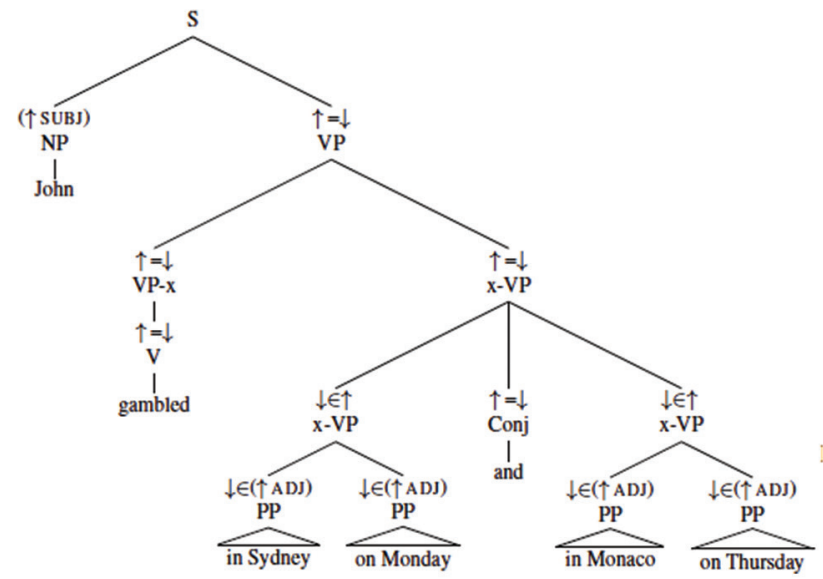

c. f-structure

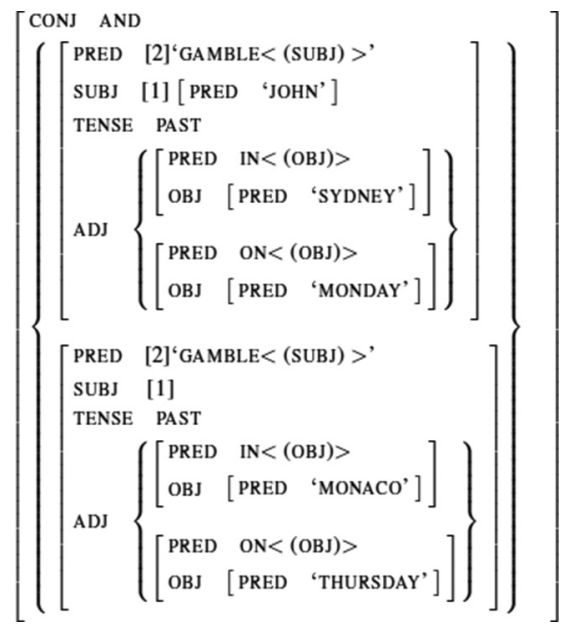


Given the internal phrase structure independence of the conjuncts, Maxwell and Manning's (1996) approach would appear to be not an appropriate tool. This is because it will interact incorrectly with distribution (29). An example illustrating this point is in below (30).

(29) Distributivity and Non-Distributivity

If $a$ is a distributive feature and $s$ is a set of f-structures, then $(s a)=v$ holds if and only if $(f a)=v$ for all f-structures $f$ that are members of the set $s$. If $a$ is a nondistributive feature, then $(f a)=v$ holds if and only if the pair $\langle a, v\rangle \in f$.

(30) $\{$ ['ali $\quad$ ya-l'ab ku: rah $] \mathrm{w} \quad[\mathrm{xa}:$ lid tennis]\}.

Ali 3m-play-ipfv football and Khaled tennis

'Ali plays/is playing football, and Khaled tennis.'

In (30), ${ }^{\varsigma} a l i$ and $y a-l^{\varsigma} a b$ will distribute into the f-structure of the second conjunct, leading to inconsistency and hence failure to produce a complete and coherent f-structure (). This violates the Wellformedness condition (31).

(31) Wellformedness Conditions

(i) Completeness

'An f-structure is locally complete if and only if it contains all the governable grammatical functions that its predicate governs. An f-structure is complete if and only if it and all its subsidiary f-structures are locally complete'

(ii) Coherence

'An f-structure is locally coherent if and only if all the governable grammatical functions that it contains are governed by a local predicate. An f-structure is coherent if and only if it and all its subsidiary f-structures are locally coherent'

(iii) Consistency

'In a given f-structure a particular attribute may have at most one value'

(Dalrymple, 2001:37\&39)

In order to avoid the problems that Albulkhari's (2016) and Maxwell and Manning's (1996) approach face, we suggest that gapping should be modeled directly in terms of f-structure sharing or function spreading, rather than distributing information associated with coordinate structure external c-structure nodes. Our analysis of gapping in TA is proposed in the following section.

\section{LFG ANALYSIS}

Before we provide an LFG analysis of gapping in TA, we first need to show how sentential coordination in this dialect is explained. Having shown that, we then provide our analysis of gapping. In Section 5.1, we will present a brief overview of the various coordination patterns available in TA, and shows how they are straightforwardly captures in the LFG analysis of coordination. Section 5.2 will present our LFG proposed analysis of gapping in TA.

\section{LFG Analysis of Sentential Coordination in TA}

As shown in the example below, it is possible to coordinate complete IP clauses in TA.

(32) $\left\{\left[\left[^{\complement}\right.\right.\right.$ ali ya-l $\left.l^{\complement} \mathrm{ab} \mathrm{ku}: \mathrm{rah}\right] \mathrm{w} \quad$ [xa: lid $\mathrm{y} \mathrm{a}-1^{\varsigma} \mathrm{a} b$ tennis]\}.
Ali 3m-play-ipfv football and Khaled $3 \mathrm{~m}$-play.ipfv tennis

'Ali plays/is playing football and Khaled plays/is playing tennis.'

The analysis of coordinate structure such as the one in (32) is very straightforward in LFG. Coordinate structures are treated as sets at f-structure due to the possibility that a coordinate structure can contain more than two members. A general schema at c-structure as (33) licenses coordinate structure.
(33) IP $\rightarrow$

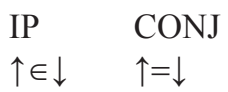
IP $\uparrow \in \downarrow$

In (33), the annotation $\uparrow \in \downarrow$ on the daughters in the coordinate IP schema states that each conjunct is a member of the set corresponding to the coordinate structure. Information associated with CONJ $(\uparrow=\downarrow)$ is contributed directly to the set itself. The c-structure (34a) shows the corresponding to the coordination in (32), together with the functional annotation associated with the coordination schema.

\section{(34) a. c-structure}

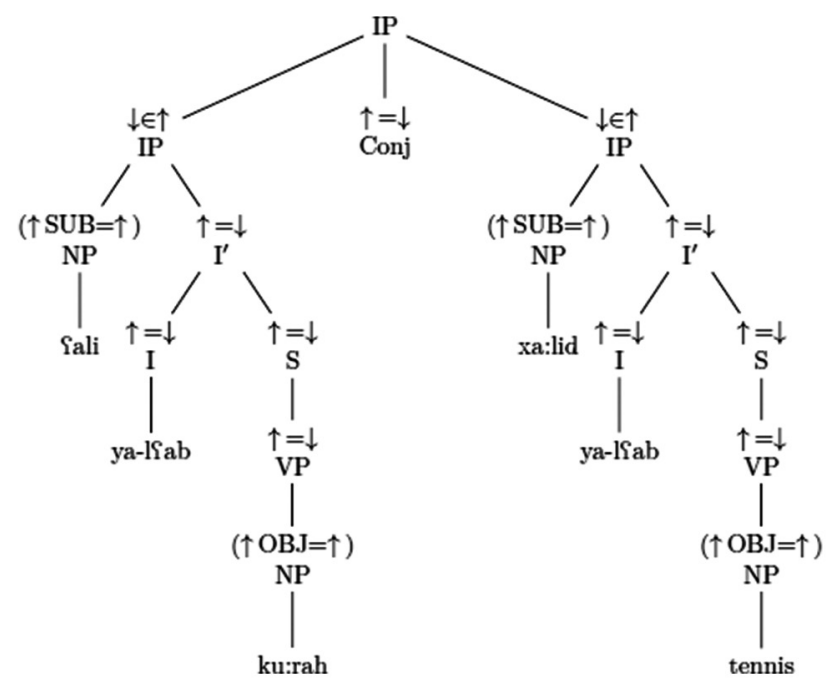

b. f-structure

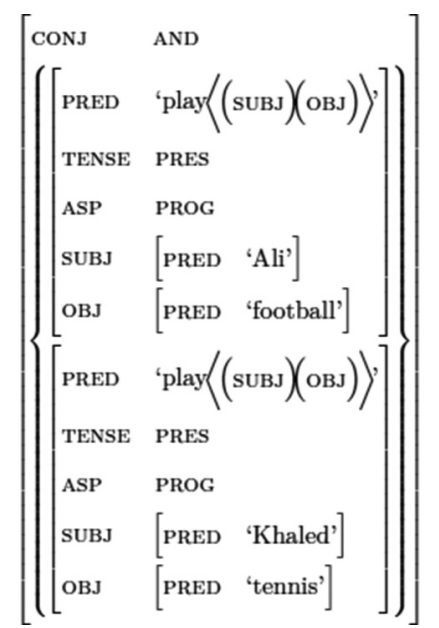

Functions introduced outside the coordination are defined over the set itself, and hence distributed to all members of the set. This is defined formally in (29) above. An example illustrating is coordination at VP level as in (35) below. 
(35)a. `ali $\quad$ w $\quad$ xa: lid yad`akun

W yal'abun.

Ali and Khaled laugh.ipfv.3pl and play. ipfv.3pl

'Ali and Khaled are laughing and playing.'

b. f-structure

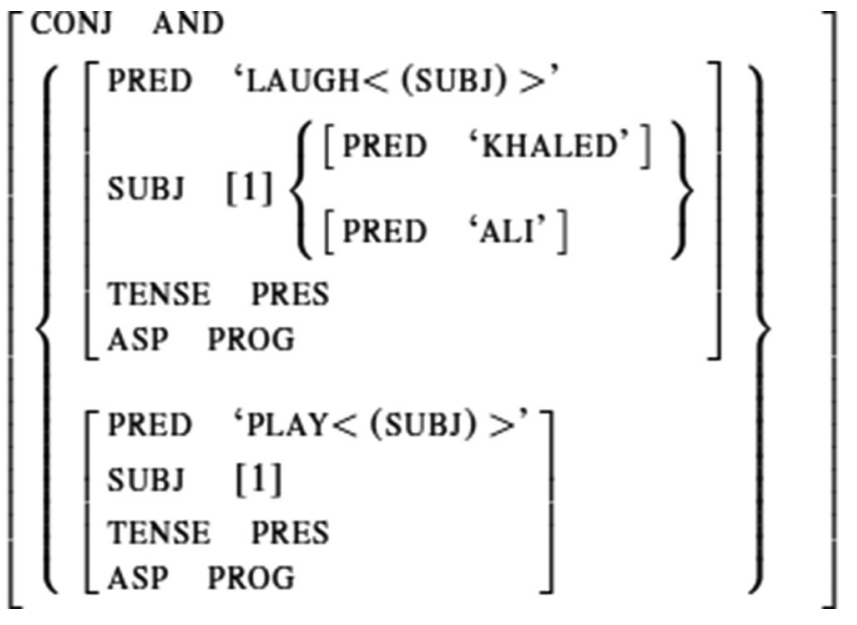

In (35b), the subject ("Ali” and "Khaled") is distributive, and hence, it is distributed over the members of the coordinate structure as observed at f-structure (35b). In the section below, we will present our proposed analysis of gapping in TA within LFG framework.

\section{LFG Analysis of Gapping in TA}

We build on Frank (2002) on Subject Gap in Finite construction in German (1) and Sadler (2006) on Asymmetrical Sentential Coordination in Welsh (2).

(36) $\{[$ In den Wald ging der Jäger] und [fing einen Hasen] $\}$ Into the forest went the junter and caught a rabitt

'The hunter went into the forest and caught a rabbit.' (Frank, 2002: 176)

$\begin{array}{rllll}\text { (37) Aeth } & y & \text { ffermwr at } & \text { drws } \\ \text { a churo } & \text { arno. } & & & \\ \text { go.past.3sg } & \text { the farmer to } & \text { the door } \\ \text { a knock } & \text { on-3sm }\end{array}$

'The farmer went to the door and knocked on it.'

In these constructions, an element, which is realized within a single conjunct, contributes information to other conjuncts.
(38) IP $\rightarrow$ IP $\quad$ CONJ IP $\uparrow \in \downarrow \quad \uparrow=\downarrow \quad \uparrow \in \downarrow$ $(\uparrow \operatorname{subj})=(\downarrow$ subj $)$
(39) $\mathrm{IP} \rightarrow$ IP $\quad$ Conj IP $\uparrow \in \downarrow \quad \uparrow=\downarrow \quad \uparrow \in \downarrow$
$(\downarrow$ subj $)=(\uparrow$ subj $)$
$(\downarrow$ tense $)=(\uparrow$ tense $)$
The hypothesis is that verbal features and grammati- cized discourse function (e.g., subj) are features, which may spread. In our example in (40), the verb spelt out in the initial conjuncts contributes information (i.e., pred and tense) to the non-initial conjunct. This is formalized in (41).
(40) ['ali ya-l'ab ku: rah] w [xa: lid tennis]\}.

Ali 3m-play-ipfv football and Khaled tennis

'Ali plays/is playing football and Khaled tennis.'

$\begin{array}{llll}(41) \mathrm{IP} \rightarrow & \text { IP } & \text { Conj } & \text { IP } \\ & \uparrow \in \downarrow & \uparrow=\downarrow & \uparrow \in \downarrow\end{array}$

$(\downarrow$ pred $)=(\uparrow$ pred $)$

$(\downarrow$ tense $)=(\uparrow$ tense $)$

The gapping construction in (40) is licensed by the schema in (41). The tree diagram in (44a) shows the corresponding to the coordination in (40), together with the functional annotation association with the coordination schema.

(42) a. c-structure

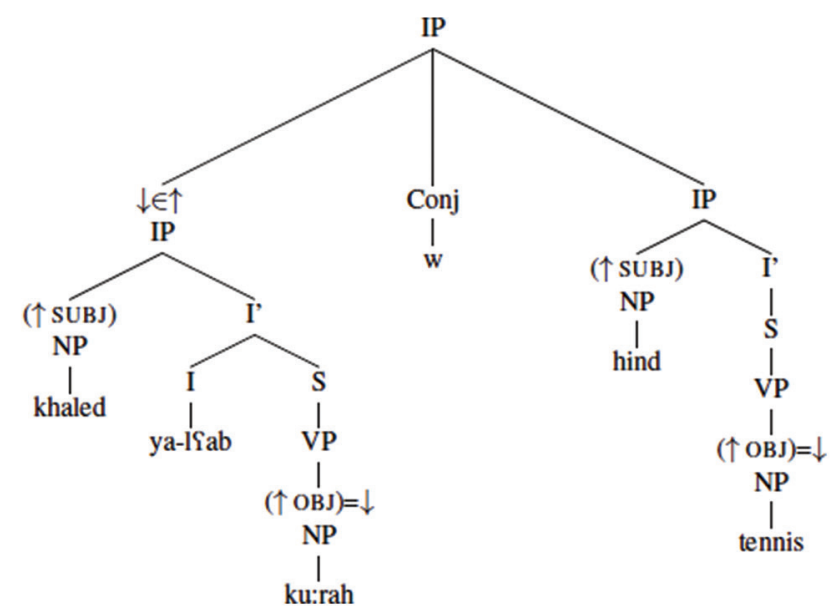

b. f-structure

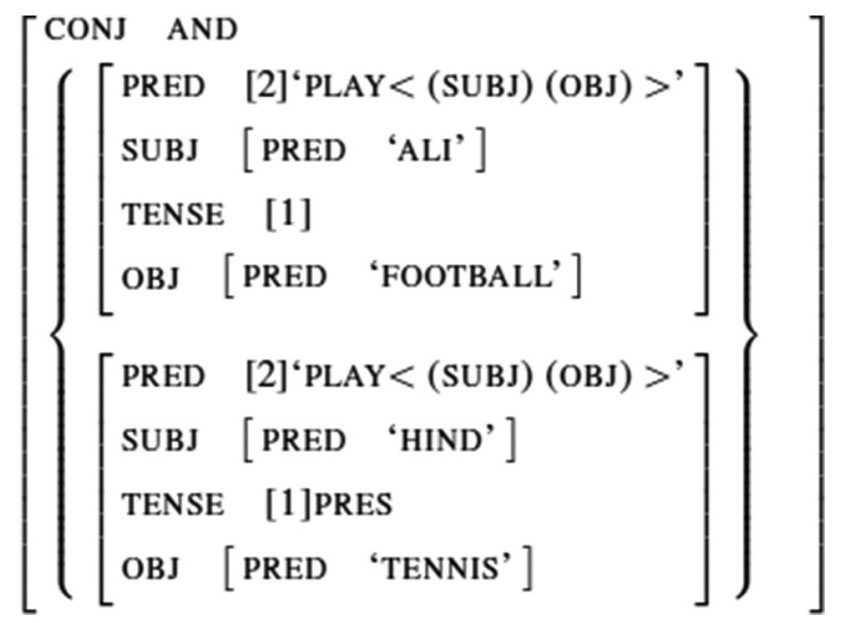

This proposed approach avoided many problems faced by the previous approaches reviewed above. First, this approach, at the level of the sentential coordination schema, is in principle independent of the sentential word order, predicting the possibility of non-matching word order in the conjuncts, as displayed in the examples in (20) above. As a result, this approach solves the problems in Johnson's (2004) and Albulkhari's (2016) derivational approach.

Furthermore, the annotation on the initial conjunct accounts for the direction of gapping, and hence, it rules out the possibility of having backward anaphora like VPE. In addition, the association of spread equation with the sentential coordination schema is independent of choice of coor- 
dinator. Therefore, this approach suggests that gapping is possible regardless of the coordinator chosen.

Moreover, the spreading equations are single level, accounting for the lack of embedding under gapping. This rules out the possibility for the gapping to operate out of or into embedded conjuncts. Also, this approach accounts for the recursive property of gapping. This is because it proposes an account based on spreading equations and the interaction of distributive features with coordination accounts.

Finally, this approach predicts the observed interaction of ATB extraction with gapping; this is because the account suggested is based on spreading equations, together with the LFG analysis of coordination and unbounded dependency constructions.

\section{CONCLUSION}

This paper has proposed analysis of gapping constructions in TA, in which the verb is expressed only in the initial conjunct. Working in LFG as a constraint-based framework, and in particular using a spreading-function approach, we show how this approach allows us straightforwardly and accurately to distribute the overtly spelt out element(s) in the initial conjunct over the members of the coordinate structure, yielding a well-formed and well-explained structure. We show how the current approach avoids the problems of the previous analyses proposed in approaches treating gapping as a result of a trace of movement, and as a non-constituent coordination.

\section{END NOTE}

1. Approaches to gapping proposed in other languages (e.g., English, Russian) exist such as gapping as a result of deletion and linearization theory in HPSG. For space limit, we cannot review all these previous approaches.

\section{REFERENCES}

Albulkhari, J. (2016). The Syntax of Elliptical Constructions in Jordanian Arabic. Ph.D. thesis Universityof Wisconsin-Milwaukee.

Algryani, A. (2011). Vp ellipsis in Libyan Arabic. Newcastle working papers in Linguistics, 17, 1-22.
Alotaibi, Y. (2014). Conditional sentences in Modern Standard Arabic and the Taif Dialect. Ph.D. thesis, Department of Language and Linguistics, University of Essex.

Dalrymple, M. (2001). Lexical Functional Grammar volume 34 of Syntax and Semantics. New York: Academic Press.

Frank, A. (2002). A (discourse) Functional Analysis of Asymmetric Coordination. In M. Butt and T. H. King (eds.), Proceeding of LFG02 Conference.

Hankamer, J. (1979). Deletion in coordinate structures. New York: Garland Publishing.

Jackendoff, R. (1971). Gapping and related rules. Linguistic Inquiry, 2, 21-35.

Johnson, K. (2004). In search of the English Middle Field. MS.

Johnson, K. (2009). Gapping is not (vp-)ellipsis. Linguistic Inquiry, 40, 289-328.

Kang, W. (1996). A Nonderivational Approach to the Gapping Phenomenon in English and Korean. Ph.D. thesis PhD Dissertation. Kyung Hee University.

Khalaf, E. A. (2015). Coordination and Linear Order. Ph. D. thesis, University of Delaware.

Lechner, W. (2004). Ellipsis in comparatives. Berlin: Mouton de Gruyter.

Levin, N. (1986). Main-verb ellipsis in spoken English. New York: Garland Pub.

Maxwell, T. T. and C. D. Manning (1996). A Theory of Non-Constituent Coordination Based on Finite StateState Rules. In Miriam Butt and Tracy Holloway King (ed.), Online Proceeding of the First LFG Conference.

McShane, M. J. (2005). A Theory of Ellipsis. Oxford: Oxford University Press.

Moltmann, F. (1992). Coordination and comparatives. Ph.D. thesis Massachusetts Institute of Technology.

Paul, W. (1999). Verb gapping in Chinese: a case of verb raising. Lingua, 107, 207-226.

Repp, S. (2009). Negation in Gapping. Oxford: Oxford University Press.

Sadler, L. (2006). Function Spreading in Coordinate Structure. Lingua, 116, 1777-1806.

Sag, I. (1976). Deletion and logical form (Doctoral. Dissertation) Massachusetts Institute of Technology, Cambridge.

Vicente, L. (2010). A note on the movement analysis of gapping. Language Inquiry, 41(3), 509-517.

Wyngærd, G. (2007). Gapping constituents: a revised version of 1998 version. MS, FWO/KU Brussel 